\title{
Accepting the Utopian Challenge: A Student Perspective
}

\author{
Breanna R. Carman \\ BS Candidate \\ University of Nebraska at Kearney
}

The scholarship of teaching and learning (SoTL) allows institutions to achieve the goals required for student learning and success. The purpose of this paper is to address recommendations for the implementation of SoTL that should have relevant input from students. These include, but are not limited to, better communication,

evaluation, continuing education, and learning networks. With the proper implementation of these recommendations, professors can effectively teach the next generation of leaders.

While the idea of a perfect university may not be achievable, the scholarship of teaching and learning (SoTL) could be. Hutchings, Huber, \& Ciccone (2011) state there has been a shift from "a college is an institution that exists to provide instruction" to "a college is an institution that exists to produce learning" ( $p$. 4). This change has been a positive one spurred by accreditation. In addition to this change, the scholarship of teaching and learning should be seen as a program to help achieve the goals required for student learning and success. Throughout their book, Hutchings et al. (2011) provide eight recommendations to help integrate SoTL into institutions. In this paper, I will reflect on those recommendations that should have relevant input from students. Considering each category, I will address why student input is critical.

As a full-time student who has taught a statistics lab as well as worked in a teaching center, I have seen firsthand the importance of communication among faculty members and between faculty members and students. Since I was partially responsible for compiling the university's new faculty orientation, I was also able to see the benefit to faculty when they were encouraged to discuss academic success and their attitudes toward SoTL.

\section{Understand, Communicate, and Promote an Integrated Vision of the Scholarship of Teaching and Learning}

\section{Terminology}

One must not forget, when promoting an integrated vision of SoTL, that students as well as professors are involved. I believe that, for students, the biggest concern is communication. If students do not have any knowledge of the vision, they are likely to be unknowingly uncooperative. The solution may be as simple as sharing the vision with students each step of the way. Once the vision to be achieved has been introduced to students, they can then understand the process and cooperate as well as give their input. In order to effectively share the vision of SoTL, professors should not focus on the terminology and the difficulty it may present but rather involve students in SoTL by explaining the necessity of their involvement in course and programmatic change.

\section{Two-Way Communication}

Communication would be less of an issue if all professors were truly invested in their teaching. It is evident when a professor views his or her role as a career rather than just a job. As a student, I appreciate when professors go out of their way to teach more than what is in the book. Taking an active interest in a student's academic career and giving each student individual attention, regardless 
of how much, can make a significant difference in the student's willingness to communicate back to his or her faculty. For example, to some students, professor evaluations at the end of each semester seem pointless. The lack of communication concerning the purpose of said evaluations has given the perception that student input is insignificant.

\section{Evaluation}

To overcome this misperception, a proper explanation to students clarifying how the evaluations will be used and what is most helpful for the professor is important. This also allows students to feel that their voices will be heard. It is imperative that the evaluations are not conveyed as a hassle that merely take up class time but instead as a tool for the professors to improve their teaching with in the future. I firmly believe that these simple changes would increase students' willingness to complete evaluations. In addition, it may be useful to include a midterm evaluation so the students have the opportunity to see change during their tenure with the faculty member. It is not uncommon for multiple students to have the same concern, but if none of them feel that their voice will be heard, they remain silent, as do their concerns. Students would appreciate an improvement in communication, in the relationship between faculty and student, and the addition of a midterm course evaluation.

\section{Support a Wide Range of Opportunities to Cultivate the Skills and Habits of Inquiry into Teaching and Learning}

\section{Continuing Education for Faculty}

It is beneficial not only for professors but also for students for colleges and universities to offer programs for professors to cultivate the skills and habits of inquiry into teaching and learning. Other teaching institutions require continuing education; why not colleges and universities? The student population is constantly changing, as are its corresponding needs. Therefore, it is important for the faculty to stay current with the changes and revamp their teaching styles or structure of their courses as needed. Institutions can encourage faculty to attend classes and workshops or participate in mentoring programs. Meeting with other faculty to discuss different strategies or implementation of certain activities can be refreshing, especially for seasoned professors.

\section{Continuing Education for Students}

Students should be given the opportunity to continue their education outside of the classroom as well. One beneficial program would have students meet with their academic advisor to assess under what circumstances they learn well (and not so well) and whether certain topics or academic areas are more difficult for them than others. This would give students the opportunity to engage in metacognition or the understanding of specific strategies that they can use to improve their academic performance. For example, advisors can apply what they know from the scholarship of teaching and learning by showing students that rehearsal is an ineffective tool for learning at the college level. As a result, students may be more likely to use a better strategy such as elaboration. Students often feel more comfortable talking to their advisors about struggling in class if they have an ongoing rapport with them. This is another example of how students can directly benefit from instructors who are willing to educate themselves about the scholarship of teaching and learning. 


\section{Connect the Scholarship of Teaching and Learning to Larger, Shared Agendas for Student Learning and Success}

\section{Connecting Learning Objectives with Life}

Students should have the opportunity to participate in out-of-class learning experiences that will increase their learning. For example, some colleges, such as the University of Nebraska at Kearney and University of North Carolina - Chapel Hill, have undergraduate research programs where students have the opportunity to work with faculty members on a research topic that interests them (Office for Undergraduate Research, 2012; Office of Graduate Studies \& Research, 2012). This gives the students the chance to gain insight and see firsthand how their academic program can be useful in the real world. The students themselves should be a part of measuring their learning and success throughout these department-, program-, and institution-wide resources. Instead of, or along with evaluating their professor, advisor, or program director, students should be asked questions specific to their learning at the end of a course or program. For this reason, professors should be sure to sell the benefit of assignments and exams to students. For example, why is one specific assignment important: What will students learn from it? Why is it important? And how will it stick with them after graduation? To accomplish this, students could meet with a faculty member to discuss the goals or major objectives that were to be accomplished and how well the student achieved them. It is important for faculty members to explain how specific learnings will help students after graduation.

\section{Take Advantage of and Engage with the Larger, Increasingly International Teaching Commons}

\section{The Need for Learning Networks}

Students are already taking advantage of and engaging in the larger, increasingly international learning commons. Before choosing classes or particular professors, students talk to one another about experiences in the classroom. This can be at the local peer level, such as between friends attending the same institution, or the larger anonymous peer level, such as ratemyprofessor.com. The former allows students to go into more detail about why they are satisfied or concerned with the professor, whereas the latter limits student ratings to how easy, helpful, and clear faculty are in their teaching (MTV Networks, 2012). The problem with talking with close friends about classes is that they often resort to complaints about professors' idiosyncrasies, or events that happened only to them rather than their overall educational climates. On the other hand, ratemyprofessor.com does not require raters to include any personal information. This becomes problematic because students performing differently (A vs. C students), or with different learning styles, majors etc., are likely to rate the same professor in vastly disparate ways. Also, this site encourages students to comment on characteristics of the professors rather than aspects of learning. This would suggest that these students care more about what their professor does in the classroom and less about how the course is structured and how that design might affect their learning (Silva et al., 2008). Another study by Otto, Sanford, and Ross (2008) found that although these ratings may be helpful, it is possible that the validity may be compromised under specific instances. For example, if the ratings reflect popular characteristics of an instructor, instructors may be working to achieve something that is successful to ratings but not conducive to higher education. 
It would be beneficial if students could meet and discuss academic issues with other students outside of their immediate peer group, yet within the same university. This could occur in one of two ways: First, the university could introduce a resource into the learning commons that allows students to formally discuss professors' teaching style, classroom structure, and student development face-toface. Second, students belonging to discipline specific extracurricular organizations (e.g., psychology club or biology student organization) could meet before academic advising begins.

\section{Develop a Plan and Time Line for Integrating the Scholarship of Teaching and Learning into Campus Culture, and Monitor Progress}

In developing a plan and time line for integrating SoTL into campus culture, one must not forget that students should be actively involved. To be effective, new policies, procedures, and courses - such as portal and capstone courses - should be explained or described in cogent terms. If students do not understand the importance of such implementations, they will be more resistant to the changes. For example, with the implementation of a new general studies program, professors should be sure to explain the importance of these additions and what students will learn from them. In regards to specific courses, professors should have specific learning objectives or goals and explain their purpose as well as how students can accomplish them. Vague learning objectives can lead to confusion and misunderstandings between the professor and student. If students were involved in changes each step of the way, it would be easier to monitor progress and make changes where needed for improvement.

\section{Recognize that Institutionalization is a Long-Term Process}

\section{Each Student's Participation}

The implementation of SoTL is not an overnight process. Professors must realize that students do not have the same personal investment in institutional change as do they. Students may not see the end result of the process or even the process itself during their time at the college or university. The average time an undergraduate student is in school to obtain their Bachelor's degree is 54 months (College Board, 2013). Institutionalization is a long-term process, and only a small amount may be achieved in that time. Therefore, it is difficult for students to see the big picture.

\section{The Future of the Student}

Implementing SoTL would no doubt require more time and energy from faculty members. However, it would be a worthwhile investment. With the goal of an institution to raise college success rates, it is important to keep the students' needs in mind. The student population changes with each incoming class, and it is important to cater to their needs without holding their hands. One approach professors can take in teaching is to think of their students as the next potential leaders in the scholarship of teaching and learning, as the next generation of leaders. With this in mind, faculty can teach students the skills needed upon graduation.

In conclusion, student involvement in the implementation of SoTL is imperative. Without it, success rates may suffer. Several steps could be taken, in addition to those previously mentioned, to include students. For example, institutions could create a student board for their center for teaching excellence departments. The students involved would determine student input and involvement as well as gauge students' reactions and suggestions. Whatever the 
case may be, student input is critical to the success of the scholarship of teaching and learning.

\section{References}

College Board (2013). Average time to a certificate, an associate degree, or a bachelor's degree: United

States. Retrieved from

http: //completionarch.collegeboard.o $\mathrm{rg} / \mathrm{completion/time-to-}$ degree/average-time-to-certificatean-associate-degree-or-bachelorsdegree-us

Hutchings, P., Huber, M.T., \& Ciccone, A. (2011). The scholarship of teaching and learning reconsidered: Institutional integration and impact. San Francisco, CA: Jossey-Bass.

MTV Networks (2012). Rate my professors. Retrieved from http://blog. ratemyprofessors.com/

Silva, K.M., Silva, F.J., Quinn, M.A., Draper, J.M., Cover, K.R., \& Munoff, A.A. (2008). Rate my professor: Online evaluations of psychology instructors. Teaching Of Psychology, 35(2), 71-80.

doi: $10.1080 / 00986280801978434$
Office for Undergraduate Research. (2012). What is undergraduate research? Retrieved from http://www.unc.edu/depts/our/

Office of Graduate Studies \& Research. (2012). Undergraduate research. Retrieved from http://www.unk.edu/academics/grad studies. aspx?id=5345

Otto, J., Sanford, D.A. \& Ross, D.N. (2008). Does ratemyprofessor.com really rate my professor? Assessment $\&$ Evaluation in Higher Education 33(4), 355-368. doi: $10.1080 / 02602930701293405$

Breanna Carman is an undergraduate student working towards her Bachelor's of Science in Psychology with a minor in Sociology at the University of Nebraska at Kearney. She has taught the Behavioral Statistics lab in the Psychology department, is working as the Human Subjects Coordinator, and is also an Undergraduate Research Fellow. Breanna also serves as the president of the Psychology Club and university's chapter of Psi Chi, the international psychology honor society. She plans to continue her education upon graduating but will to take a year to explore her interests in the field of psychology and start a family. 